\title{
Recovery Period of Fluvial Sediment Transport after a Major Earthquake
}

\author{
Guan-Wei Lin $^{1 *}$ and Hsien-Li Kuo ${ }^{1}$ \\ ${ }^{1}$ Department of Earth Sciences, National Cheng Kung University, Taiwan \\ *Corresponding author: Guan-Wei Lin, Department of Earth Sciences, National Cheng Kung University, Taiwan
}

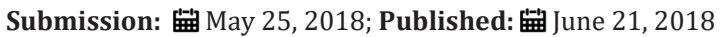

\begin{abstract}
Fluvial sediment transport reflects the rate of geomorphic change in river catchment. By retrospection long-term observation data of fluvial sediment, the recovery period of sediment transport after a large earthquake can be assessed. We proved that the recovery period in a given catchment is positively correlated with the peak ground motions triggered by an earthquake. The correlation indicates that a recovery period of more than four years is required if a catchment is affected by an earthquake with a ground acceleration greater than 400gal. Major earthquake is an important factor for sediment yield, especially within a few years after a large earthquake. Therefore, within a few years after a major earthquake, fast geomorphic change in river catchment should be considered as one of environmental conditions for engineering and natural-disaster prevention work.
\end{abstract}

Keywords: Recovery period; Fluvial sediment; Earthquake; Unit concentration

\section{Introduction}

Intense earthquakes will not only cause sudden great damage in the neighborhood region, but also trigger a consequent effect of mass wasting. Taiwan is located at the convergent boundary of the Eurasian Plate and Philippine Sea Plate with crustal shortening of approximately $90 \mathrm{~mm} / \mathrm{yr}$ [1], and more than twenty earthquakes with magnitudes of 5.0 occur per year. The specific geologic setting of Taiwan provides the opportunity to understand the duration of an earthquake's influence on mass wasting. The amount of sediment transport in rivers is commonly used to represent mass wasting. The amount of material transported in the rivers around Taiwan has been reported in many studies. Li [2] reports that the average denudation rate in Taiwan is at least $1365 \mathrm{mg} / \mathrm{cm}^{2} / \mathrm{yr}$, corresponding to erosion rate of $4 \mathrm{~mm} / \mathrm{yr}$, which is one of the highest in the world. Dadson et al. [3] compared the variability of sediment discharges before and after the 1999 Chi-Chi earthquake and found that the central region of Taiwan was located near the epicenter, so the average sediment discharge after the earthquake increased by 4.4 times. Additionally, Lin et al. [4] and Chung et al. [5] found that the amount of suspended sediment discharges from two major rivers in the central region of Taiwan increased more than four-fold after the 1999 earthquake.

Some studies reported the influence of a major earthquake on fluvial sediment transport for a given impacted region. Koi et al. [6] found that the impact of the $1923 \mathrm{Mw}-7.9$ Kanto earthquake on the sediment yield in the catchments close to the epicenter could last for more than 80 years. Hovius et al. [7] report that the $1999 \mathrm{Mw}$ 7.3 Chi-Chi earthquake had an impact period of approximately 6 years on the amount of sediment transport to the Choshui River in central Taiwan. However, the discussion on the variations of sediment transport under different impact levels is limited. We attempt to discover the period required to restore the sediment transport to pre-earthquake levels in several catchments affected by earthquakes with different scales of vibration. The values of recovery period of sediment transport may be an important reference for considering engineering strategy of catchment management or natural-disaster prevention work within a few years after a major earthquake.

\section{Results and Discussion}

The sediment concentration data used in this study are mainly from the Water Resources Agency (WRA) of Taiwan. The WRA staff collected river water samples two to three times a month near river hydrometric stations using a DH-48 full-depth sampler and measured the sediment concentration [8]. As in most rivers, the suspended sediment concentration Cs (ppm) is related to water discharge $Q\left(\mathrm{~m}^{3} / \mathrm{sec}\right)$ through a power law, $C s=\kappa Q^{\mathrm{b}}$, where the exponent $b$ is determined by the availability and mobilization of sediment and $\kappa$ is the suspended sediment concentration at the unit water discharge [7]. The rating-curve method based on the Cs- $Q$ power law relation is one of the most common estimation methods for suspended sediment discharge $[9,10]$, especially in the case of 
insufficient hydrometric data. The observed hydrometric data were collected from eleven major rivers around Taiwan (Figure 1).

We used sediment concentration data from the Peinan River in southeastern Taiwan to establish the Cs-Q rating curves for preand post-earthquakes and compared the variation of suspended sediment discharges before and after the earthquakes. In the Peinan River, the value of $\kappa$ was 43.16 ppm before the 2003 Chengkung earthquake and increased to $76.14 \mathrm{ppm}$ after the earthquake (Fig- ure 2). This showed that sediment transport increased by 1.8 times after the earthquake. The average annual runoff from the Peinan River during the period from 1948 to 2003 was $3.0 \mathrm{~km}^{3} / \mathrm{yr}$, and the average annual sediment discharge was $57.77 \mathrm{Mt} / \mathrm{yr}$. During the period from 2004 to 2008, the average annual runoff was 2.92 $\mathrm{km}^{3} / \mathrm{yr}$ and the average annual sediment discharge was $82.01 \mathrm{Mt} /$ yr. This exhibited that the annual sediment discharge increased by 1.4 times after the 2003 earthquake at a similar water discharge.

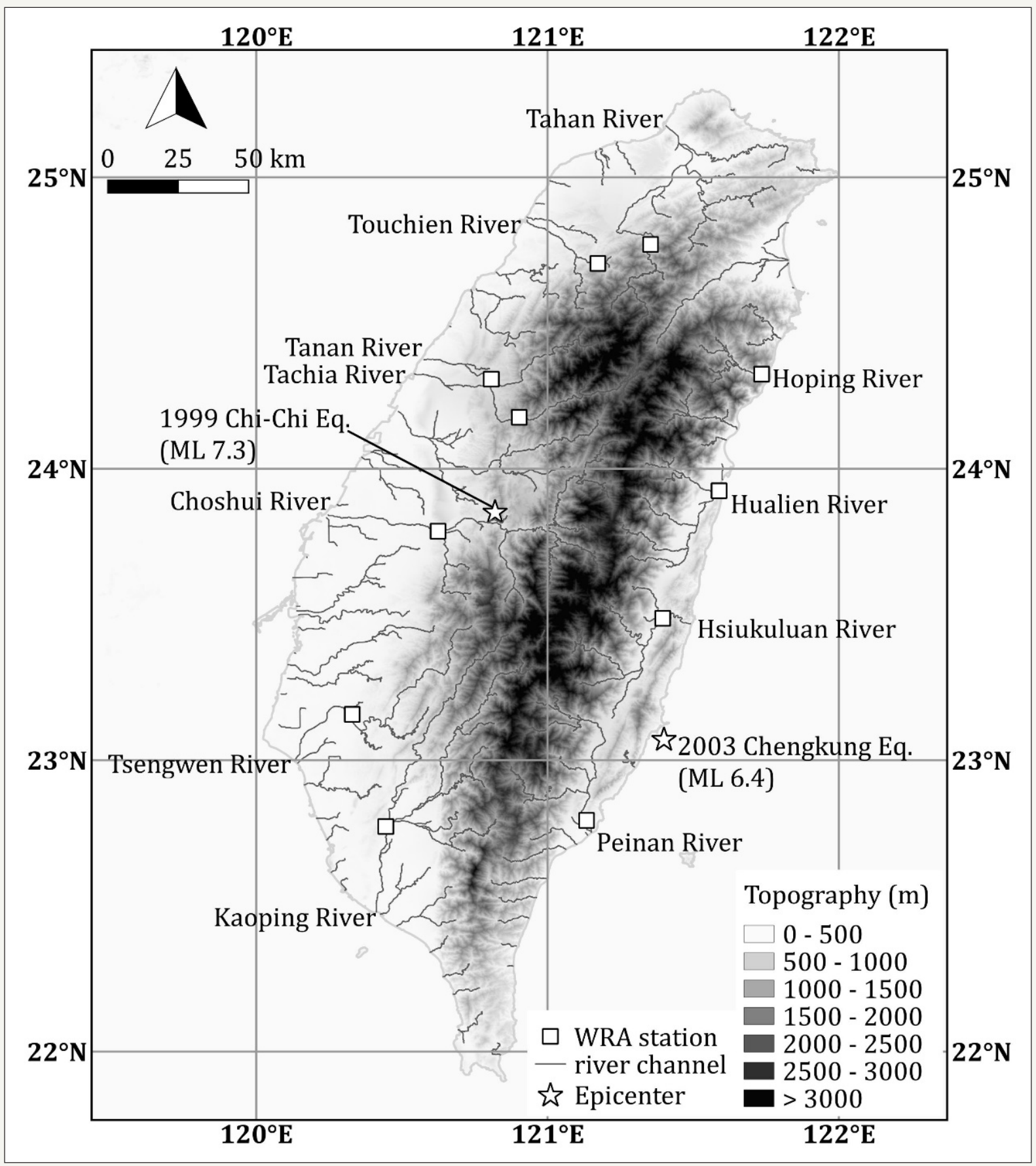

Figure 1: Distribution of rivers and hydrometric stations. The star symbols represent the epicenters of the 1999 Chi-Chi earthquake and 2003 Chengkung earthquake. 


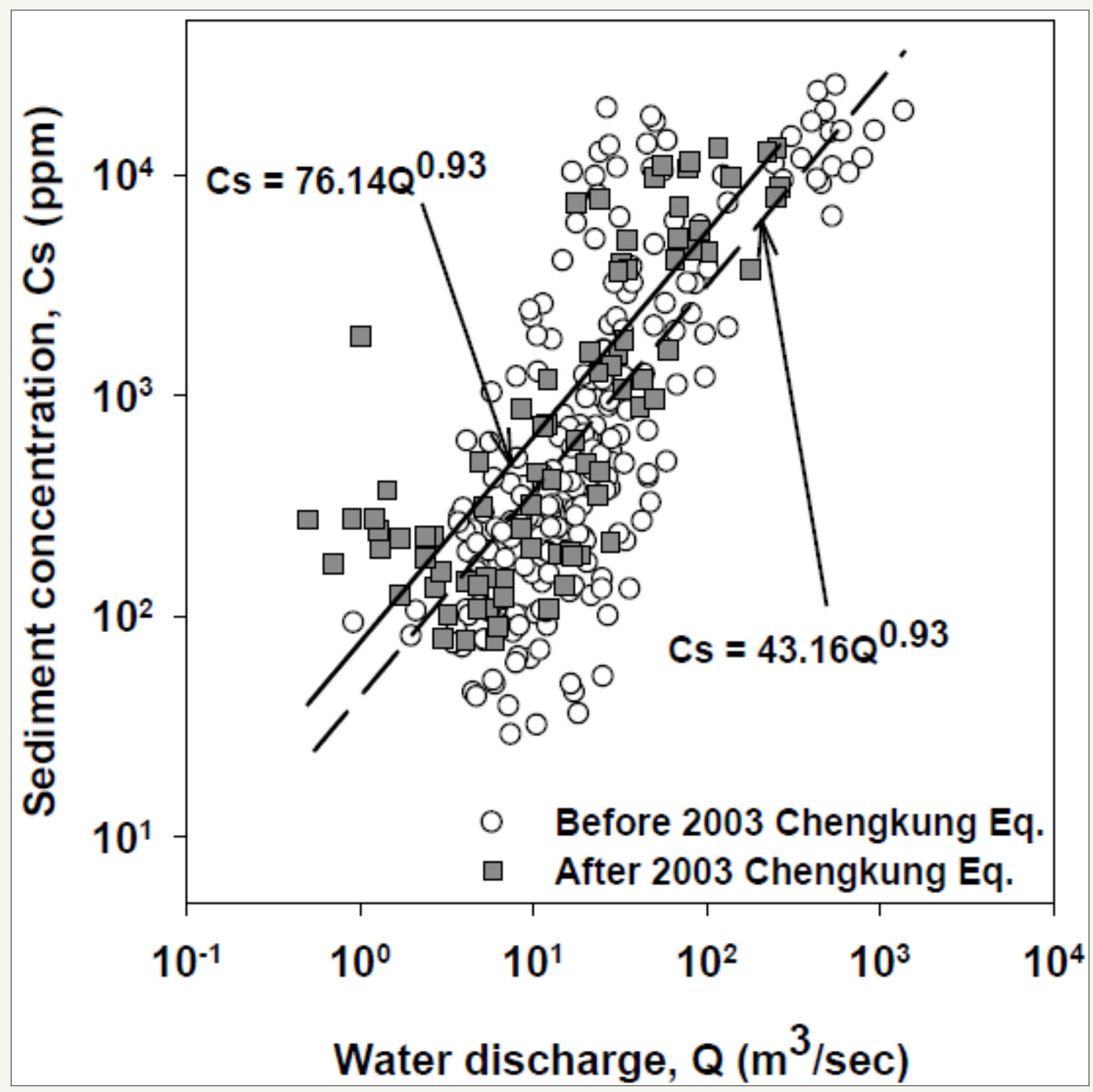

Figure 2: The Q-Cs relationships before and after the 2003 Chengkung earthquake in the Peinan River.

The impact of a large earthquake on the mass wasting in a basin will not terminate in a short period, as was the case in the 1923 Kanto earthquake in Japan, which affected the amount of sediment discharge in the Sakawa River for 80-100 years [10]. To understand the time needed to return to the level of the average sediment discharge before an earthquake, we attempted to use the measured sediment concentration data during the typhoon period to obtain the unit concentration, $\kappa$, during typhoon seasons and the yearly average $\kappa$ (Figure 3). After a large earthquake, most of the catchments showed a rise in unit concentration during a subsequent typhoon event. This indicated that the loosening of geomaterial and the increase of sediment supply in the catchment resulted in the increase of sediment concentration in the river. Since the $1999 \mathrm{Chi}-$ Chi earthquake, the unit concentrations in the main rivers around Taiwan had increased, and the ground motions in different river catchments were different, so the influence degrees were also different.
Furthermore, the ratio of unit concentration after the earthquake to the average value before the earthquake can be calculated. We assumed that the unit concentration had returned to the pre-earthquake level when the ratio was less than 1.0. In this way, the recovery period could be obtained for the unit sediment concentration to return to the mean value before an earthquake. From the examples of several rivers, it can be seen that the annual runoff of the Touchien River in 2000 was $0.26 \mathrm{~km}^{3}$ and the annual runoff of the Chenyoulan River in 2000 was $0.54 \mathrm{~km}^{3}$, which were obviously lower than their average values of 0.31 and $0.73 \mathrm{~km}^{3}$, respectively. Therefore, after the 1999 earthquake, the unit concentration in the two rivers did not increase immediately. In contrast, the annual runoff of the Peinan River in 2000 was $3.32 \mathrm{~km}^{3}$, which was greater than the average of $3.01 \mathrm{~km}^{3}$. Therefore, the unit concentration in 2000 was higher than the average before the earthquake. The results showed that the unit concentration of sediment transport did not necessarily exhibit an immediate increase in the subsequent year after an earthquake. 

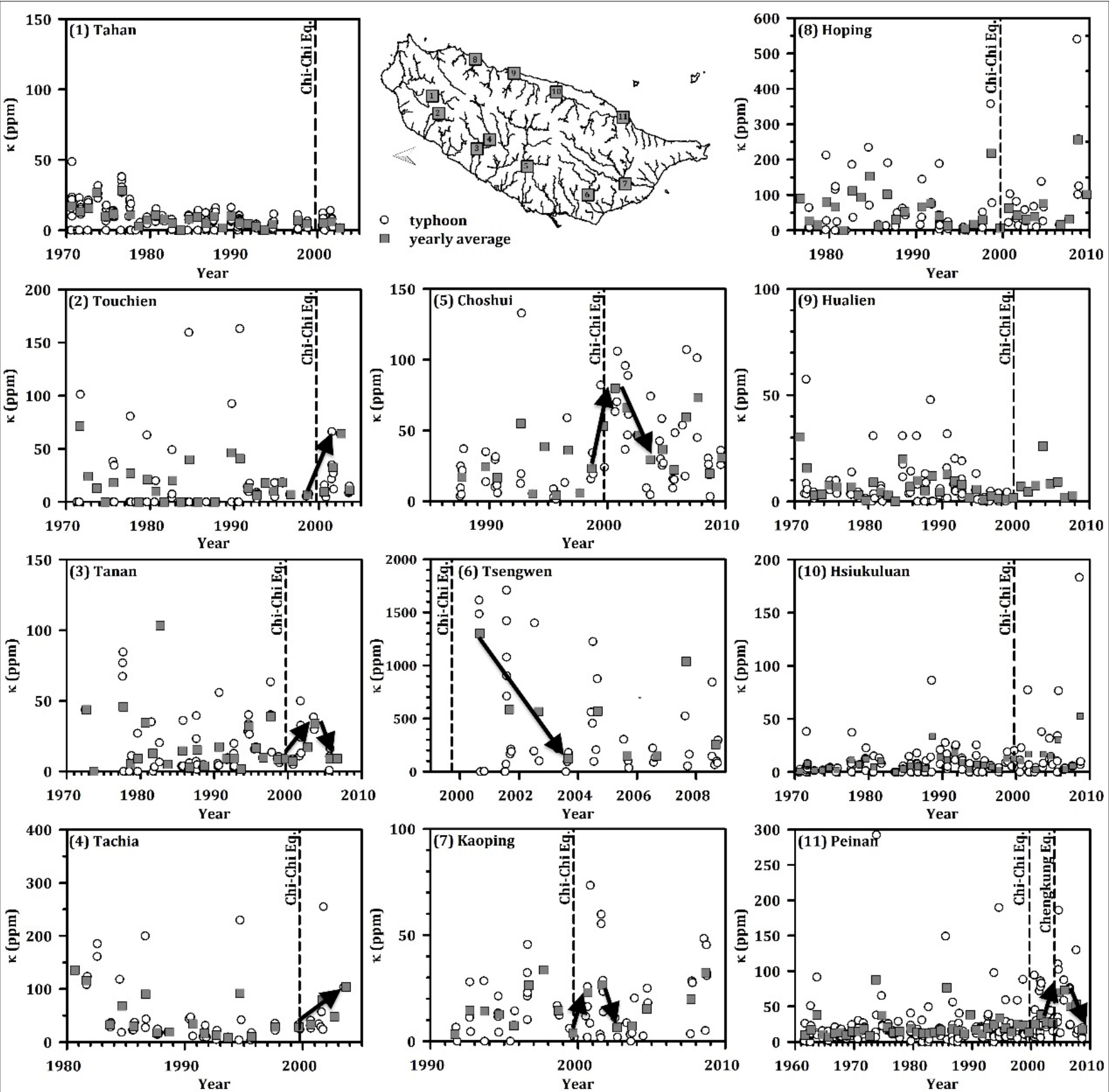

Figure 3: Time series of unit sediment concentrations, $\kappa$, in the major rivers around Taiwan.

In addition, the ratio, $\Delta \kappa$, of unit concentration after two before an earthquake revealed that the unit concentrations in the Touchien River returned to the average before the 1999 earthquake in 3.9 years, and the unit concentration in the Chenyoulan River returned to the average before the earthquake in 6.3 years (Figure 4). In 1999 and 2003, the Peinan River experienced two large earthquakes, the Chi-Chi and Chengkung earthquakes. The unit concentration returned to the average before the 1999 earthquake in 3.4 years and returned to the average before the 2003 earthquake in 4.1 years.

We collected data on the peak ground acceleration (PGA) caused by the 1999 Chi-Chi earthquake, the 2003 Chengkung earthquake, and the 2006 Taitung earthquake, as well as the recovery periods of the unit concentrations of several catchments. By comparing the peak ground acceleration and recovery period in each catchment, we learned that when a catchment was affected by an earthquake with peak ground accelerations greater than 100 gal, the recovery period of sediment supply in the catchment was more than 2 years (Figure 5). Furthermore, a recovery period of more than four years was required if a catchment was affected by an earthquake with a peak ground acceleration greater than 400 gal. The time required to return to the pre-earthquake level of sediment supply was longer due to greater ground acceleration. The results showed that the 
recovery period of the sediment transport after a large earthquake in Taiwan was significantly shorter than that of the Japanese rivers. This can be attributed to the following reasons: the annual precipitation, $>3000 \mathrm{~mm}$, in Taiwanese mountain areas is more than that of the Sakawa River basin, $1662.5 \mathrm{~mm}$, and the lengths of the main streams of Taiwanese rivers are shorter than the Sakawa River. Therefore, in Taiwan the geomaterials affected by earthquakes were prone to transport to downstream areas and even the ocean.

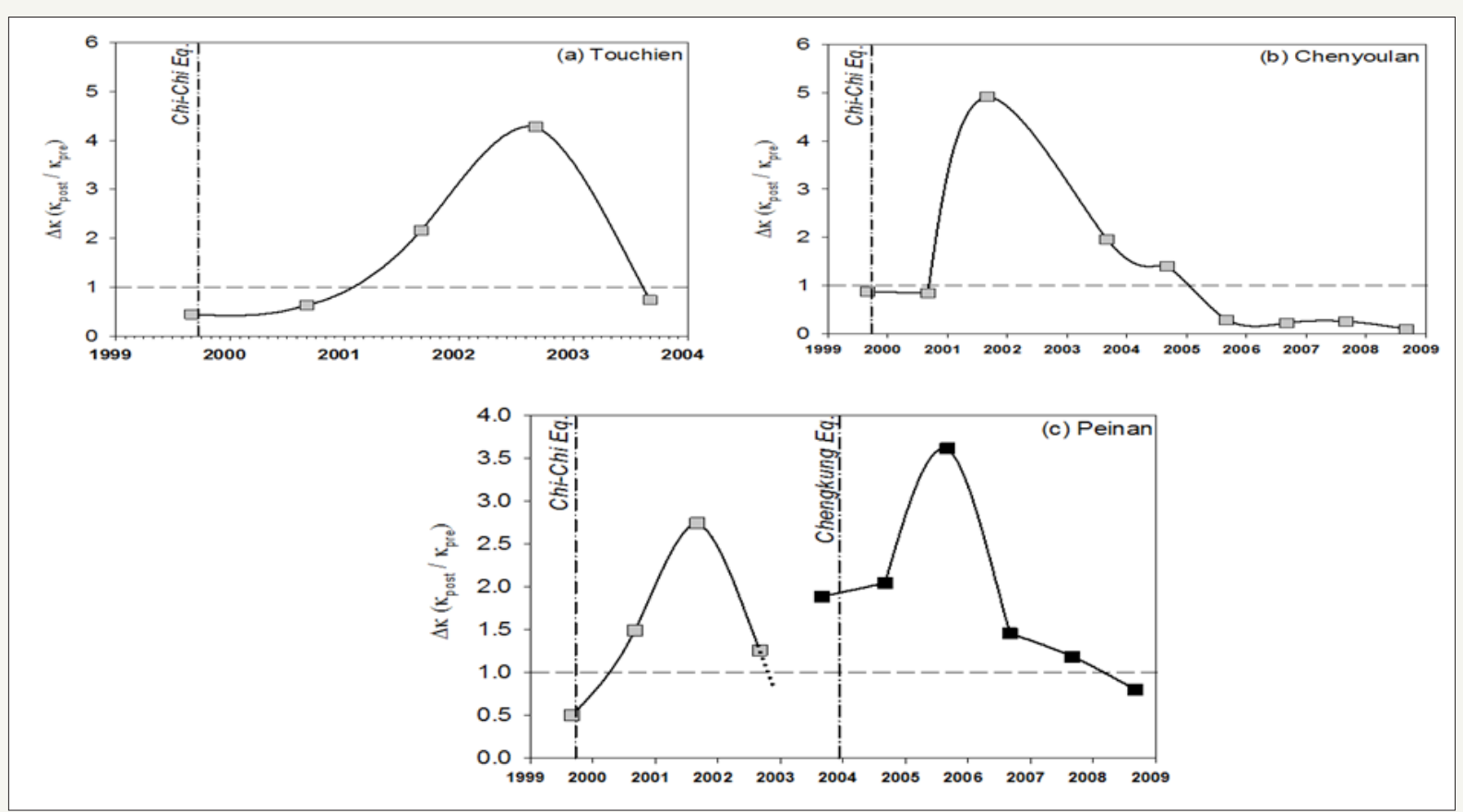

Figure 4: Variations of the ratio, $\Delta \mathrm{k}$, of unit concentration in (a) Touchien River, (b) Chenyoulan River, and (c) Peinan River.

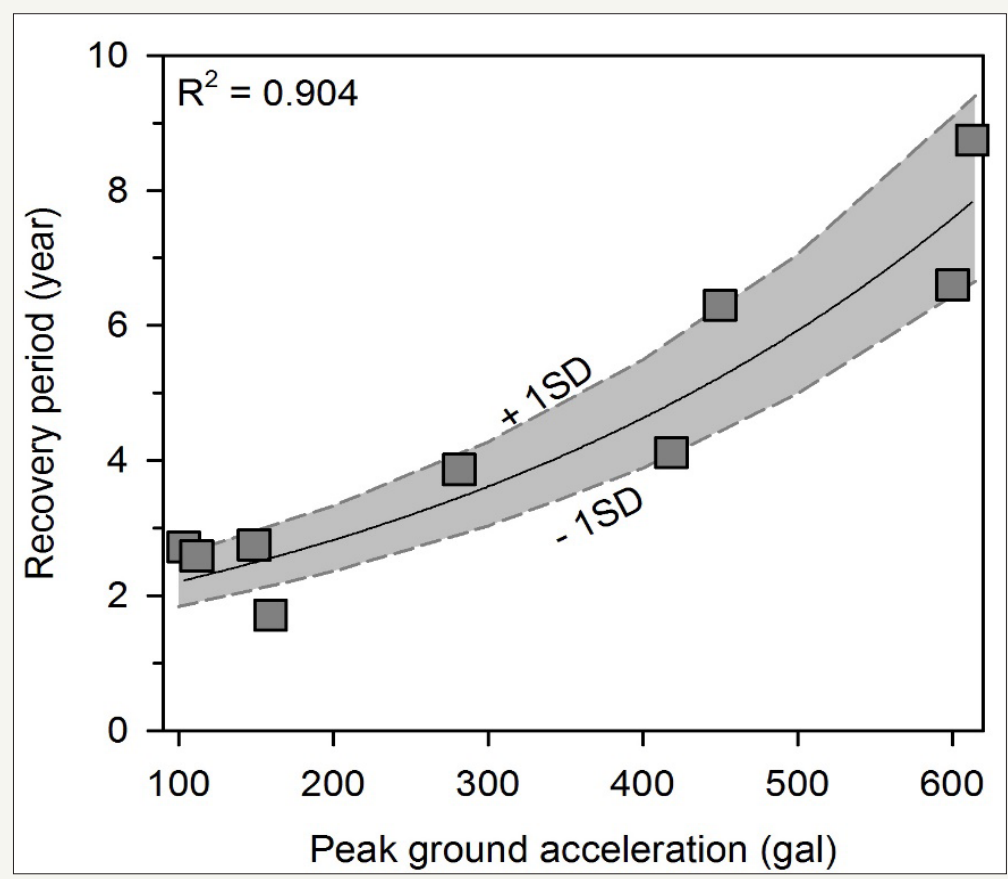

Figure 5: Relationship between peak ground accelerations and recovery periods. SD means standard deviation.

\section{Conclusion}

The sediment concentration data of the main rivers in Taiwan were used to assess the change of unit sediment concentration be- fore and after a large earthquake, which reflects the impact of the earthquake on sediment yields. The ground motions triggered by an earthquake in different catchments were different, so the influences on sediment yields could be significantly different. The ra- 
tios of unit sediment concentrations prior to and following a large earthquake in a catchment can be used to assess the recovery period. The relation between recovery periods of fluvial sediment transport and PGAs revealed that the time required to return to the average sediment concentration before an earthquake was longer due to the greater surface acceleration of the earthquake. When a catchment was affected by an earthquake with a PGA greater than $400 \mathrm{gal}$, the required recovery period was more than 4 years.

\section{Acknowledgement}

This work was supported by the Ministry of Science and Technology, Taiwan. We thank the officers and crews of Water Resources Agency, Ministry of Economic Affairs, for supplying the hydrometric data.

\section{References}

1. Sella GF, Dixon TH, Mao A (2002) REVEL: A model for Recent plate velocities from space geodesy. J Geophys Res 107(B4): 2081.

2. Li YH (1976) Denudation of Taiwan Island since the Pliocene epoch Geology 4: 105-107.

3. Dadson SJ, Hovius N, Chen H, Dade WB, Lin JC, et al. (2004) Earthquake- triggered increase in sediment delivery from an active mountain belt. Geology 32: 733-736.

4. Lin GW, Chen H, Chen YH, Horng MJ (2008) Influence of typhoons and earthquakes on rainfall-induced landslides and suspended sediments discharge. Engineering Geology 97: 32-41.

5. Chuang SC, Chen H, Lin GW, Lin CW, Chang CP (2009) Increase in basin sediment yield from landslides in storms following major seismic disturbance. Engineering Geology 103: 59-65.

6. Koi T, Hotta N, Ishigaki I, Matuzai N, Uchiyama Y (2008) Prolonged impact of earthquake-induced landslides on sediment yield in a mountain watershed: The Tanzawa region, Japan. Geomorphology 101: 692-702.

7. Hovius N, Meunier P, Lin CW, Chen H, Chen YG, et al. (2011) Prolonged seismically induced erosion and the mass balance of a large earthquake. Earth and Planetary Science Letters 304: 347-355.

8. WRA (1970-2015) Hydrological Yearbook of Taiwan. Water Resources Agency, Ministry of Economic Affairs: Taiwan.

9. Cohn TA (1995) Recent advances in statistical methods for the estimation of sediment and nutrient transport in rivers. Reviews of Geophysics 33: 1117-1123.

10. Kao SJ, Chan SC, Kuo CH, Liu KK (2005) Transport- dominated sediment loading in Taiwanese rivers: a case study from the Ma-an stream. The Journal of Geology 113: 217-225.

\section{Submit Article}

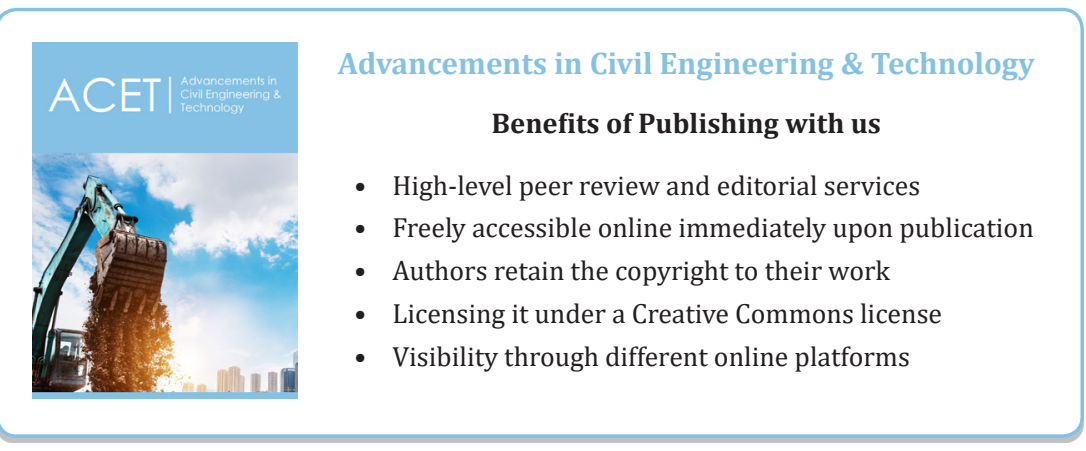

